https://doi.org/10.48009/2_iis_2009_536-543

\title{
PROTOTYPING FOR THE HOLY GRAIL OF RFID: RETURN ON INVESTMENTS
}

\author{
Vic Matta, Ohio University, matta@ohio.edu \\ Kevin Berisso, Ohio University, berisso@ ohio.edu \\ Tod Brokaw, Ohio University, brokaw@ohio.edu
}

\begin{abstract}
The suitability of application Radio Frequency Identification (RFID) Systems in the supply chain has been discussed since the late nineties. Like any new innovation, there are advantages (in operational efficiencies), and disadvantages (in its implementation). The hype created by this innovation suggests that advantages outweighed the disadvantages. Yet, adoption has lagged most predictions. This paper makes the case that one of the key causes of this is the lack of expected returns on investment (ROI). ROI is treated as cost-benefit factor, which can take many forms, and therefore can be measured in different ways by different parties. The paper goes on to discuss various intricacies of achieving ROI and attempts to frame the circumstances under which it is most likely to be found. The paper identifies combinations of closed loop versus open loop and item level versus pallet level circumstances for manufacturers, suppliers, and retailers in the supply chain, and evaluates ROI opportunities for each. Based on the resulting misaligned interests of supply chain partners, a three stage "natural" RFID adoption process is proposed.
\end{abstract}

\section{INTRODUCTION}

With the announcement that they would require their top 100 vendors to place radio frequency identification (RFID) tags on incoming pallets by 2005, Wal-Mart initiated a firestorm of activity. Since their announcement, and the accompanying realization by suppliers that they would have to start using RFID, companies have been trying to determine if and where they would be able to find true value in using RFID. And with this, RFID technology has been spoken of in context of its applicability to manufacturing, logistics, and retail organizations since the late nineties [31]. Diversity of competing transponder technologies and lack of standards created barriers to easy acceptance and application of the technology in supply chain organizations [18]. Benefits and challenges of the technology were also recognized early $[14 ; 21]$, and setting the stage for discussions along a multitude of angles - from discussion of its business cases [7; 14] to dialogues about its hype [2]. A review of published peer-reviewed journals provides little direction or evidence of successful ROI for RFID. A search for the terms RFID and ROI within search engines such as Ebsco Host and Compendex result in numerous hits, but very few that are from refereed journals most results are from industry magazines or other web based resources. At the same time, one constantly hears of case studies and stories where companies have successfully found ROI for RFID. So where is the evidence? Arguably the reason for so few documented examples is the simple fact that companies do not want to share their successes in detail since it gives away a competitive advantage[10].

A manuscript published by AIMGlobal, aptly documents the timeline of RFID prior to the $21^{\text {st }}$ century [19]. While the beginning of RFID can be traced back to World War II, experimentation with the technology in more public scenarios didn't begin until after 1950. Commercial applications were explored in the late eighties. Debates and discussion about RFID systems began in the nineties with emergence of initial standards for use of RFID in logistics. Until then, the dialogue focused on technological and logistical issues, such as evaluating Wifi frequencies [8] and standardizing them towards specific supply chain applications. The first commentaries $[5 ; 6 ; 10]$ on benefits challenges began in the early 2000s, slowly shifting the focus away from technical issues. Although there still remained technological issues, the discussion adopted a more holistic approach by including a business focus [1]. The business case for RFID has since been centered on cost-benefit analyses, or Returns on Investment (ROI) [30]. While most supply chain organizations had trouble coming up with a model that justified ROI, Wal-Mart was one of the first to find a return on its investments [9]. Based on a solid business model, the retailer announced a mandate to require their top 100 suppliers to adopt pallet-level tagging by 2005 . This need for compliance with Wal-Mart's mandate jump started adoption of RFID systems [26] across the supply chain, albeit not for expectations of good ROI [35] for all organizations. While this was the case in 2005, ROI has been an important and 
unanimous consideration for companies considering an un-mandated implementation of RFID systems for logistical applications, and the debate has now moved to whether RFID technology can bring about ROI $[11 ; 12]$, when it would be expected to bring ROI [20;29], and how it could be achieved [22;33; 36; 37]. This newer trend towards increasing discussion on ROI makes a case for a meta-discussion - that takes a step back to first define what ROI means in context of RFID system implementation within supply chain organizations, discusses the challenges in its assessment, and attempts to frame the contexts in which ROI has been found and can be expected.

The adoption of RFID is a strategic decision. For unfettered, un-mandated, adoption to take place an organization must be able to justify the cost of the investments in the technology in terms of when and how they could expect to reap the benefits of that investment. In most cases, these benefits have a direct impact on the bottom line, the savings. It is therefore a primary driver for such voluntary and nostrings-attached adoption. For this reason, ROI has been called the Holy Grail for an RFID enabled Supply Chain [13].

\section{LITERATURE REVIEW}

There is no shortage of discussion on ROI with RFID. However, there appears to be little peer reviewed literature that summarizes and illuminates a framework of circumstances where ROI is achieved and therefore may be expected. Articles that do exist $[3 ; 4 ; 15]$ seem to discuss limited components of the overall picture or only stress small segments within both a company and the supply chain. Before beginning a search for ROI in this context, it makes sense to fully understand what is meant by ROI. Therefore this discussion begins with explaining what ROI is and how it is assessed.

\section{What is ROI}

At its core, ROI is a cost-benefit analysis, and takes into account anything that may hold value - whether it is financial or non-financial. Definitions of ROI vary with the contexts of the investments they work with. A traditional representation of ROI focuses on financial benefits (such as cost reductions and/or revenue increases). Increasingly, contemporary estimates of ROI have been including more than just financial benefits. These non-financial benefits often take different forms, such as competitive advantage for a third party logistics provider who may use that to advertise efficient distribution of goods and InTransit-Visibility (ITV). Since ROI has many forms with varied levels of tangibility, it is important to identify ROI elements with direct financial components, for initial calculations.

The most basic calculation of ROI and also the most commonly used form is known as Simple ROI. This is a ratio of revenue against the original investment made for the project. Revenue (also known as Cash Flow) is the difference between financial benefits less the costs of the project. This simple version is used in single period calculations. There is also a more evolved version that incorporates the time value of money, in the form of the Payback Period (i.e. the time taken to pay back the cost of the project), and the Net Present Value (or the value of future benefits in today's terms). As implied by its name, this calculation, involves an interest rate for calculating the time value of money, and presents ROI as an Internal Rate of Return (IRR), or more simply, benefits restated as an interest rate. The point to note here is that ROI is inversely proportional to the time it takes to achieve. IRR (the ROI including time value) is greater when returns occur over a shorter period. In Figure 1 [25] below, time is on the $\mathrm{X}$-axis, cash flow on the Y, and IRR is represented by the slope of the line traced by the extremities of the bars.

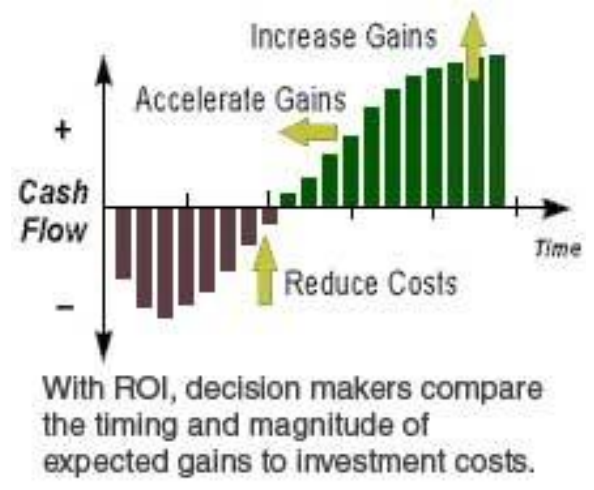

Figure 1: Financial ROI[25]

Assessing the non-financial ROI can be difficult. In order to fully realize ROI, a company needs to consider all returns or benefits of their investment. In some cases, Investments may not have a directly equitable monetary value. For example, it is difficult to apply a dollar value to a satisfied customer, or good customer service. In other cases, such intangibles can be transformed into monetary values. For instance in the case of a provider of mobile software for distribution companies, time is money and a savings in time is a big part of the business case [37]. Since different evaluators would place different values on such cases, especially in changing economies, these values are best accounted for as 
they are and without further transformation. Nonfinancial ROI, therefore is accepted as largely qualitative, typically ungeneralizeable, and is best used in comparative contexts when other circumstances are constant.

While dealing with costs, the term: Total Cost of Ownership (often Operation) or TCO, is most often used during ROI calculations to imply the inclusion of costs beyond those immediately visible, and therefore "total" costs. These include costs of overhead activity created by the disruptive innovation, such as retraining and relocation of personnel, reestablishment of business processes, or even the time spent in investigation of product fit for the business, or selection of system integrators. Consider the case of the retail test conducted by Proctor and Gamble at Wal-Mart using RFIDenabled end-of-aisle displays for their Venus razor blades two weeks before Mother's Day [23]. The cost of this exercise included cost of display, personnel time in training on and working with the system, software implementation (cost and installation), opportunity cost, and the management of business intelligence and related reporting systems, fees charged by Wal-Mart for the trial. As expected much of this is difficult to assess.

Moreover, any attempt to do so is not completely generalizable since no two system implementations are identical.

A few trade journal articles have attempted to capture the less tangible components of RFID system implementations, by revealing costs and savings of changes in the form of a laundry list[27], or by consolidating hidden costs as TCO. In either case, the challenge in assessing ROI still remains because no two RFID system implementations identical. A review of several cases for assessment of ROI reveals some consistent patterns for achievement of ROI. The discussion in the next section explores the different categories of classification in which ROI has been found. These include ROI across levels of implementation, supply chain partners types, and across open versus closed loops implementations.

\section{RESEARCH AND ANALYSIS}

Review of literature on ROI of RFID implementations shows achievement of ROI has been spoken of along different categories. Some articles suggest that ROI varies by level of implementation or by type of supply chain industry, while others suggest that ROI is simply characteristic of closed or open loop systems. These are discussed in more detail below.

\section{Across Levels of Implementation}

This category describes implementation from the perspective of level of focus and detail [11] at which RFID systems are implemented. It has four subgroups: Autonomous, Intra-firm, Inter-firm, and Supply chain system-wide. (i) Autonomous implementations are done for discrete processes to overcome the shortcomings for a contemporary technology, system or process. In such cases the system (hardware/software) and process requirements have specific and focused goals, unaffected by external constraints. Although this increases the chances of success, the smaller size of implementations has smaller benefits and ROI. (ii) Intra-firm implementations extend from single discrete processes into other processes within boundary of the company. This adds complexity and risk of new constraints, but under strict control of (technological and process) standards and environmental conditions (such as radio signal interference), often well-aligned and clear objectives (from the manager of one company versus several). Such intra-firm deployments inherently have strict process control, and increased utilization of the RFID software system. In some cases, there is increased utilization of mobile readers/scanners, and tags on reusable totes. Since there is a small increase in costs (due to increased complexity of process, hardware and software), and a relative larger increase due to labor efficiencies and error reductions, the results are impressive. (iii) Inter-firm implementations involve synchronization of RFID standards and processes across select partner firms in the supply chain process. Since it involves external firms, enforcement of process options and automation, selection of standards (for readers, tags and their placement) can be limited by constraints of different firms. The increase in complexity in inter-firm implementations is offset by benefits of inter-firm visibility of assets. This translates to vendor managed inventory that is of great advantage to retailers and upstream supply chain partners. The trade-off in terms of ROI is still good, since the environment is still more controlled than a system-wide implementation.(iv) System-wide implementation of RFID technology is a vision suggesting the ubiquitous use of this technology with standardized tags and readers that are adaptable to entities and processes in their value chain. A fully efficient RFID enabled supply system is beyond the capabilities of the current technology. However, the Electronic Product Code standard (EPC), and WalMart's mandates are pushing the envelope towards an implementation at this level [11]. 
This breakdown of implementation levels show that there is a lower amount of risk for RFID system implementations that are discrete (or autonomous) and intra-firm, and medium to high for those that are inter-firm and system-wide, respectively. Further, maturity of the technology and labor for smaller implementations is higher. This suggests that to increase chances of achieving good ROI, implementations must start small.

\section{Across Open and Closed Loop Systems}

Open Loop systems are those in which technologies, their formats, standards, and processes must be shared across organizational boundaries. Supply chain organizations use one of the largest open loop systems and use well established bar code and/or RFID systems for distribution of goods to retailers. When specifications of standards and formats are specific to one organization and independent of any others, the system is considered to be a closed loop. In general, the requirements of closed loop implementations are extracted from within the same organization and are therefore fewer, less constrained, allow for more choices, and use simpler processes. This typically results in a lower TCO, and therefore a substantially better ROI [33].

\section{Across Supply Chain Partners}

The core Supply chain organizations: manufacturers, logistics providers, and retailers, face different ROI propositions [28]. From a supply chain perspective, manufacturers are required to bear the cost of purchasing, affixing and writing data to the tags onto outgoing pallets, and do not see direct or clearly tangible ROI. For logistics providers, though there is a high level of variation in requirements due to the involvement of a larger number of supply chain partners, they mostly benefit from RFID systems because incoming pallets are already tagged, and they do not have recurring costs of RFID tags. Retailers see operational efficiencies in delivery and inventory systems, and therefore realize ROI over a shorter term. Since supply chain organizations can implement both open and closed loop types of RFID systems, it makes sense to review the incidence of ROI from a combined perspective.

Manufacturers - Open Loop Systems: For the case of open loop implementations of RFID systems in manufacturing, the only RFID activity is in the labeling of goods prior to their shipment (a.k.a. slap$\mathrm{n}$-ship), i.e. at the end of the manufacturing value chain. The manufacturer incurs costs for placing tags on items, for enabling their internal software to collect, organize and send data to their business partners [24]. It is typically the recipient of the product who benefits from the RFID implementation [24; 34]. Unless they are able to derive savings or profit from the added costs of implementing the RFID system, the manufacturer only ends up paying. The results of this are that for most manufactures, there may be little if any ROI to be found in implementing an open loop solution.

What seems to be one of the few open loop approaches that may provide a benefit to manufacturers is the approach to RFID ROI that is being taken by the Automotive Industry Action Group (AIAG). In their B-18 Returnable Transport Item Tracking RFID Pilot Whitepaper, they discuss the use of RFID to better track returnable transport containers. Based on a 2005 AMR Research report which indicated $\$ 750$ million per year was being spent on replacing totes and racks within the automotive industry [15]. In this use case, the identification of ROI becomes much easier since the loss of a transport container can be easily identified and hard numbers exist. Additionally, manufacturing down time, penalties due to late shipments and other actual dollar costs can be identified for inclusion in the ROI calculations.

Manufacturers - Closed Loop Systems: Based on the white papers and case studies reviewed, it seems that the best method for achieving ROI by manufacturers is through the use of closed loop systems where the manufacturer is able to better track internal items. In one white paper, Intermec (a bar code and RFID hardware vendor) argues that "manufacturers should look inward at their operation's own business processes, not forward into just supply chain customer's compliance requirements" [16]. Intermec goes on to argue that since working with the manufacturer's supply chain partners results in a significantly more complex system, looking internally for uses can result in simpler, and therefore less expensive, implementations. In manufacturing, tracking of work in process, raw materials and product genealogy seem to be common themes [17]. For example, by tracking of consumable items like drill bits, cutting inserts and sand-paper, companies have the ability to better ensure that their supplies are stocked and save money though a reduction in manhours for determining what needs to be replenished.

Logistics Providers - Open loop systems: Third party logistics providers (3PLs) will often see much more of an advantage from open loop systems than from closed loop applications since they are usually working with multiple companies. While there is an 
argument for some closed loop activities (discussed below), the main advantage seems to be in the 3PL's ability to acquire information out of the RFID tag without the expense of placing on the tag on the item. By using tags already applied to items, the 3PL company could determine what is on a tag, where the tag should go, any special handling requirements and could provide value-added in-transit visibility to both the sending and receiving parties without a lot of added expense. However, like the retailer that will be discussed later, the value comes from already having the tags applied to the items and the ability to have an open standard in which the related information can easily be obtained.

Logistics Providers - Closed loop systems: In these circumstances, ROI is uncertain, especially for complex implementations. For instance, good ROI was found with companies like FedEx, Dalsey, Hillblom and Lynn (DHL) and the United Parcel Service (UPS) who make an extensive use of closed loop solutions. In fact, the bulls-eye bar code on UPS packages was originally called UPS code, provided fair ROI [32] as long as cost and application of tags wasn't a part of the calculation. There are fewer applications in closed loop systems that have demonstrated a fast ROI. One that deserves a mention is in trailer tracking in large yards, where the entry time and location of trailers might be needed by the yard management team. In a white paper [3], Intermec discusses how Old Dominion Freight Lines uses RFID successfully. However, in the overall scope of things, this seems like a relatively small ROI opportunity.

Retail - Open loop systems: Retailers such as WalMart are typically able to find ROI with their implementations, albeit on the backs of their suppliers [15]. Balanced against the lack of lost earnings are the costs of EPCGlobal membership (the costs are dependent on location, company size and other factors), the calculation of savings directly attributable to RFID are complicated at best. Despite this, there is a powerful argument for the use of RFID as a more efficient enabler for the electronic data interchange (EDI) activities that many companies engage in. By allowing users to unload products without having to scan pallets, time is saved. In addition, since EDI is an open system, there already exists an infrastructure for the passing of information between partners and within a company's computer systems.

Retail - Closed loop systems: For retail companies, the use of closed loop solutions are similar to manufacturing/processed-based companies, with the same benefits. Since larger companies will have the same problems and assets as many other companies (such as material handling equipment, information technology assets, etc.), the same arguments for the use of closed loop solutions applies here as well.

Figure 2 below summarizes the discussion thus far.

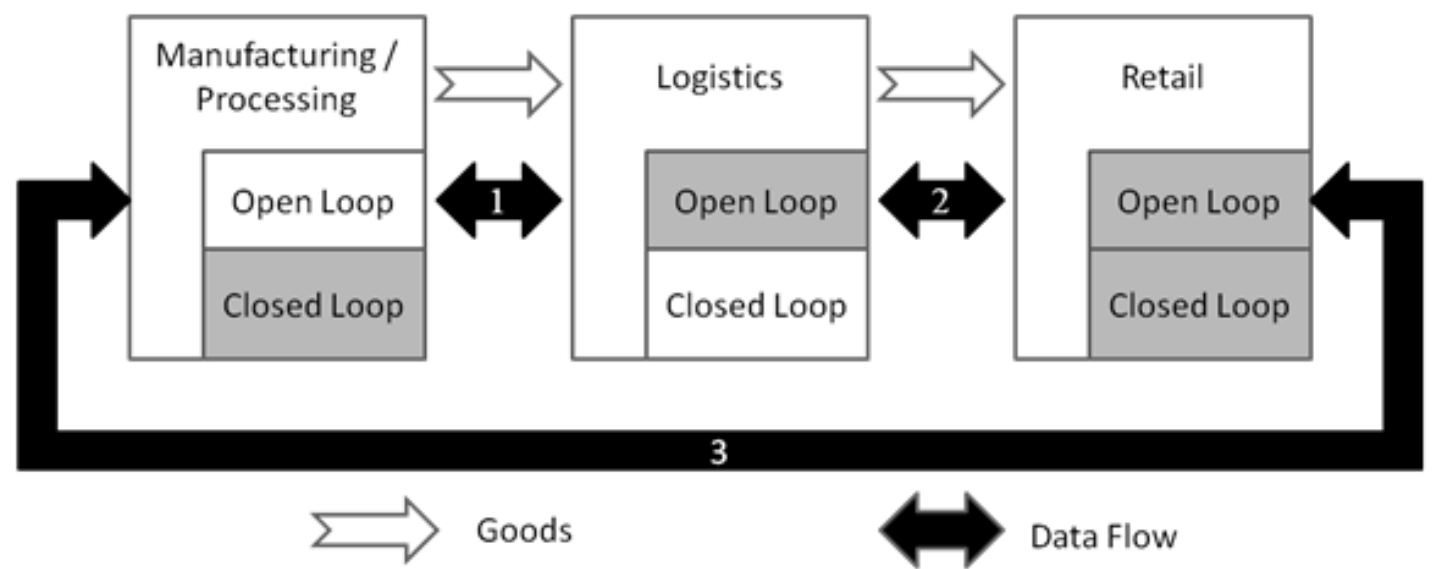

Figure 2. Model of how and where ROI may occur shown by shaded areas

\section{Analysis: Three stages of RFID adoption}

As noted earlier, adoption of RFID technology has been slower than expected. There are numerous possible reasons for this, but it may be the case that misaligned business interests among players in the supply chain are one of the causes. From an ROI perspective, manufacturers' current interest is in closed loop, item level implementations of RFID. Suppliers largely have an interest in open loop, pallet level applications of the technology. Retailers potentially have ROI potential in both closed 
loop/item level and open loop/pallet level RFID applications. The result of these differing interests is adoption of RFID that is fragmented and not wellcoordinated across an industry's supply chain. Fully integrated and ubiquitous adoption of RFID within an industry will likely occur over a period of time during which manufacturers, suppliers, and retailers first pursue self interest, then work through a variety of supplier/buyer influences to find shared interest, and finally through a stage of optimization and additional specialized applications of RFID technology.

Stage One - "Self Interest" (Present Stage): Supply chain participants' current decisions to pursue RFID adoption are driven by self interest in terms of generating ROI. The first stage of adoption, then, is largely characterized by companies focusing investment in RFID systems that can deliver a return by improving their own internal processes. In this stage, shared returns with supply chain partners are a secondary concern.

Manufacturers will implement closed loop, item level RFID applications that improve their core production processes. These systems are focused on optimizing the management of materials, parts, and finished goods inventories for the manufacturing company itself. Logistics providers, on the other hand, have more interest in receiving goods from manufacturers, delivering goods to retailers, and effectively managing wholesale inventory along the way. Hence, their RFID investment focus is characterized primarily as open loop/pallet level application. Retailers can benefit from both closed loop/item level and open loop/pallet level RFID applications, and so their interest is characterized by a focus on both. Retailers stand to benefit from both types of RFID use, but they are potentially faced with the problem that the use of RFID is only as good as what is flowing downstream in the chain from manufacturers and logistics providers.

The resulting natural evolution of RFID adoption in the first stage, then, is a somewhat uncoordinated, fragmented, non-integrated approach by the various supply chain partners. It does need to be acknowledged here that there are supplier/buyer power forces at play in some industries that have and will continue to alter the natural evolution to some degree (e.g., Wal-Mart as a retailer forcing the adoption of RFID upstream in their supply chain, regardless of the ROI potential for everyone in that supply chain). However, the dynamics of any discreet supply chain are different, and the stage one (fragmented, self-interested) RFID adoption will prevail in most cases.

Stage Two - "Shared Interest": Led by logistics providers and retailers, both of whom have an interest in open loop RFID systems, supply chain members will eventually gain ROI from their self-interested applications, and evolve toward more integrated, shared applications. Of course, implicit in this "shared" stage, there will remain the fundamental self-interested business focus on ROI for the individual firm. But the means to obtaining that ROI will shift to a shared, partnering-oriented perspective.

Manufacturers will largely resist open loop/pallet level RFID investment until suppliers (and in some cases retailers) become willing to share in RFID investment with the manufacturers. Suppliers will have made their own investments in open loop applications during stage one, yet these systems will remain sub-optimized and will not generate the full ROI potential of ubiquitous, fully integrated RFID systems that is possible. Retailers also will become more open to sharing in the benefits of fully integrated RFID with upstream suppliers. Stage two will be characterized by increased negotiations among supply chain players to not only share in the investment requirement of implementing fully integrated systems but also a marked increase in the sharing of cost-savings and other benefits.

Stage Three - "Optimization and Advancement": Stage three will be characterized by both selfinterested and shared interest investment in RFID applications. Once the self and shared interests among supply chain partners are moderated through stage two and core process RFID integration occurs, all the players in the supply chain will focus on optimizing the existing RFID applications in order to gain the most benefit for their various investments. Additionally, "next-generation" add-on technologies will be developed and gain attention. This stage will be characterized by supply chain - wide initiatives, such as advanced vendor managed inventory and advanced in-transit visibility. It will also be characterized by new add-on applications such as smart shelving in retail stores and warehouses.

Table 1 shown on the following page describes the three stages of RFID adoption. 


\begin{tabular}{|l|l|l||l|l||l||}
\hline & \multicolumn{2}{|l|}{ Stage 1 } & \multicolumn{2}{|l||}{ Stage 2 } & Stage 3 \\
\hline Manufacturer & $\begin{array}{l}\text { Closed Loop } \\
\text { only }\end{array}$ & Item Level only & $\begin{array}{l}\text { Open and } \\
\text { Closed Loop }\end{array}$ & $\begin{array}{l}\text { Item and Pallet } \\
\text { Level }\end{array}$ & $\begin{array}{l}\text { Vendor Managed } \\
\text { Inventory }\end{array}$ \\
\cline { 1 - 2 } $\begin{array}{l}\text { Logistics } \\
\text { Providers }\end{array}$ & $\begin{array}{l}\text { Open Loop, \& } \\
\text { at times Closed }\end{array}$ & Pallet Level & $\begin{array}{l}\text { Open and } \\
\text { Closed Loop }\end{array}$ & $\begin{array}{l}\text { Item and Pallet } \\
\text { Level }\end{array}$ & In-transit Visibility \\
\cline { 1 - 4 } Retailers & $\begin{array}{l}\text { Open and } \\
\text { Closed Loop }\end{array}$ & $\begin{array}{l}\text { Item and Pallet } \\
\text { Level }\end{array}$ & $\begin{array}{l}\text { Open and } \\
\text { Closed Loop }\end{array}$ & $\begin{array}{l}\text { Item and Pallet } \\
\text { Level }\end{array}$ & $\begin{array}{l}\text { Smart Shelf } \\
\text { Applications }\end{array}$ \\
\hline
\end{tabular}

\section{CONCLUSION: IMPLICATIONS FOR MANAGEMENT}

Managers of organizations in the various positions of the supply chain should pursue RFID applications that support their own internal processes and self interests, yet also keep an eye toward future shared interest opportunities. One of the benefits of RFID technology itself is the flexibility of data types that can be captured and tracked via RFID tags. It is possible that internal applications, if designed appropriately, can be adapted for more shared supply chain purposes in the future. Thus, even closed loop systems developed today may help deliver additional $\mathrm{ROI}$ in future open loop shared applications.

Managers of manufacturing businesses should seek opportunities to leverage RFID to drive ROI in their internal production processes and also in their finished goods inventory management processes. Additionally, they should be aware of and pursue opportunities to negotiate with downstream partners for shared benefits that can result particularly from their item level finished goods RFID applications.

Logistics providers should invest in open loop/pallet level RFID applications that help them optimize receipt, management, logistics, and distribution of products. Managers of logistics firms should invest in these types of RFID use in order to improve their bargaining position with upstream and downstream partners that will likely occur in stage two of RFID evolution.

Given that retail management stands to ultimately benefit from both closed and open loop applications of RFID, they should carefully evaluate their current position in industry and leverage it in order to foster upstream RFID development as best as possible. Current self-interested investment should focus on positioning their operations to gain as much as possible from both self-interested and shared interest investments being made by their upstream partners.
Though the current stage one development of RFID will largely be driven by internal self interest, a recognition of possible future shared benefits as adoption moves to stages two and three is important. This dual perspective will allow management at all supply chain positions to not only gain valuable short-term benefits but will also, and perhaps more importantly, reduce the long term total cost of shared ownership of fully integrated RFID systems. Success of this second goal will depend on the ability of various players to minimize "throw-away" implementations by designing internal applications that adapt well to shared applications.

\section{REFERENCES}

1. Asif, Z., \& Mandviwalla, M. (2005). Integrating the supply chain with RFID: a technical and business analysis. Communications of the AIS, 2005(15), 393-426.

2. Atkinson, W. (2003). Web-Based RFID: Hype and Glitz? Operations \& Fulfillment, 11(9), 2932.

3. Beyond the Tag: Finding RFID Value in Manufacturing and Distribution Applications. (2007).

4. Borthick, A. F., Bowen, P. L., \& Gerard, G. J. (2008). Modeling a business process and querying the reuslting database: Analyzing RFID data to develop business intellegence. Journal of Information Systems, 22(2), 331-350.

5. Brandel, M. (2004). The Trouble With Tags. Computerworld, 38(51), 32-33.

6. Burnell, J. (2000). The Jury's Out. Frontline Solutions, 1(6), 18.

7. The Business Case for RFID. (2001). Modern Materials Handling (Vol. 56, pp. 90): Reed Business Information.

8. Choi, Y. B., Park, J.-Y., Park, J.-Y., \& Kim, K.B. (2005). Recent Wireless LAN Management Technologies: Trends and Outstanding Issues. Issues in Information Systems, VI(1-2).

9. Cooke, J. A. (2005). Slow but Steady. Logistics Management, 44(2), 30-34. 
10. Duris, R. (2004). "Dirty Little Secrets" of RFID. Frontline Solutions, 5(10), 42-42.

11. Fontanella, J. (2004). Finding the ROI in RFID. Supply Chain Management Review, 8(1), 13-14.

12. Fontelera, J. (2006). Can RFID bring ROI? Converting Magazine, 24(4), 4-4.

13. Fontelera, J. (2007). Quest for the RFID SupplyChain Holy Grail: ROI. Converting Magazine, 25(9), 35-35.

14. Gould, L. S. (2000). What You Need to Know About RFID. Automotive Manufacturing \& Production, 112(2), 46.

15. Hardgrave, B. C., Langford, S., Waller, M., \& Miller, R. (2008). Measuring the Impact of RFID on Out of Stocks at Wal-Mart. MIS Quarterly Executive, 7(4).

16. Hill, S. (2007, March 2007). What to do while waiting for RFID to pay off. Manufacturing Business Technology.

17. How Mobile RFID Systems Improve Operations and ROI. (2007).

18. Howell, S., Butler, I., \& Zeitlhofer, D. (1998). The Holy Grail - Standards and RFID. Automatic I.D. News Europe, 7(2), 29.

19. Landt, J. (2001). Shrouds of Time: The History of RFID. Pittsburgh: AIM, Inc.

20. Malykhina, E. (2004). RFID ROI? Not Soon. InformationWeek(1012), 14-14.

21. Matta, V., \& Moberg, C. (2006). The Development of a Research Agenda for RFID adoption and Effectiveness in Supply Chains. Issues in Information Systems, 7(2), 246-251.

22. McClenahen, J. S., \& Purdum, T. (2004). RFID's ROI. Industry Week/IW, 253(11), 67-67.

23. McCrea, B. (2006). Where's the ROI? Logistics Management, 45(11), 49-52.

24. McWilliams, G. (Feb 15, 2007). Wal-Mart's Radio-Tracked Inventory Hits Static. Wall Street Journal (Eastern Edition), p. 81.

25. Return on Investment: What is RIO Analysis? Cost-Benefit Analysis, from http://www.solutionmatrix.com/return-oninvestment.html

26. Sheffi, Y. (2004). RFID and the Innovation Cycle. International Journal of Logistics Management, 15(1), 1-10.

27. Smart, L. (2004). Making Sense of RFID. Library Journal, 129, 4-14.

28. Smyrlis, L. (2005). The "glass pipeline" is clearly in sight. Now How about the ROI? Canadian Transportation \& Logistics, 108(11), 60-62.

29. Spiegel, R. (2004). Cost reduction, not ROI, is near-term goal. Supply Chain Management Review, 8(8), 85-85.
30. Standards, New Frontiers and ROI. (2004). Consortium Standards Bulletin, 3(1), 24-25.

31. Supply Chain Management. (1998). Management Services, 42(5), 4-4.

32. Terdiman, D. (2008). UPS and the art of sorting nearly a million packages a day.

33. Trebilcock, B. (2007). Pinpointing the ROI in RFID. Packaging Digest, 44(6), 48-49.

34. Uncover the ROI in RFID...Closed Loop Systems Provide Savings. (2009).

35. Webster, J. S. (2008). Wal-Mart's RFID Revolution - A Tough Sell. Network World, 25(36), 34-36.

36. Wheatley, M. (2008). Learning to track ROI. Manufacturing Business Technology, 26(9), 2830.

37. Witt, C. E. (2006). Real-World ROI for RFID. Material Handling Management, 61(5), 26-31. 